\title{
Reminder induced by training cues and stimulation of the mesencephalic reticular formation
}

\author{
TERRY L. DEVIETTI and BRIAN KIRKPATRICK \\ Central Washington University, Ellensburg, Washington 98926
}

\begin{abstract}
Compared to a standard group of animals fear conditioned by a single presentation of a tone paired with strong footshock, retention is reduced in animals implanted unilaterally in the mesencephalic reticular formation (MRF) and conditioned by pairing the tone and strong footshock, in animals implanted and conditioned by pairing the tone with strong footshock and then given electroconvulsive shock and in animals implanted and conditioned by pairing the tone with weak footshock. Reminder treatments consisting of the factorial combinations of exposure to training cues (present or absent) and stimulation of the MRF (present or absent) differentially increased retention performance in these three basic groups. Memory storage and memory retrieval explanations of these data are discussed.
\end{abstract}

The notion that the administration of an electroconvulsive shock (ECS) after a training trial disrupts memory consolidation processes (Glickman, 1961; McGaugh, 1966) has weathered a long history of alternate interpretations (viz, Coons \& Miller, 1960; Lewis \& Maher, 1965; Spevack \& Suboski, 1969). The most recent alternative to this pervasive explanation, and by all indications the most serious, seeks to explain experimental anmesias as resulting from a disruption of memory retrieval systems (Lewis, 1969, 1976; Miller \& Springer, 1973).

As there are little data available regarding the mechanisms involved, the meaning of the terms "storage" and "retrieval" are necessarily vague and we must be content with a conceptual distinction. Our view is that the memory process must involve, minimally, an input and an output process. On balance, we use the term "storage" to refer to the input side of the process and the term "retrieval" to refer to the output side of the process.

Explanation in terms of memory retrieval appears to be supported by a host of studies which show increased retention in ECS animals following a "reminder" treatment that is interpolated between training-ECS and the test (e.g., DeVietti \& Hopfer, 1974; Lewis, Misanin, \& Miller, 1968; Miller \& Springer, 1972; Quartermain, McEwen, \& Azmitia, 1970). The reminder treatment usually consists of some of the elements of the training situation, e.g., training cues and/or the unconditioned stressor. As

This research was supported in part by National Science Foundation Grant BM573-07038-A01. We thank Gary Conger, Bill Reeder, and Tim Wittman for their help with the project. Requests for reprints should be sent to Terry $L$. DeVietti, Department of Psychology, Central Washington University, Ellensburg, Washington 98926. such, these studies have not proved convincing to some investigators, who maintain that the reminder data actually support a consolidation explanation (Cherkin, 1972; Gold, Haycock, Macri, \& McGaugh, 1973; Haycock, Gold, Macri, \& McGaugh, 1973; Kesner \& Conner, 1974). These latter investigators argue that the reminder treatments constitute an additional learning trial, the memory of which generalizes to and summates with a memory remnant which survived the treatment used to effect amnesia. Support for this generalization hypothesis comes from studies in which the degree of retention increased by the reminder treatment varies inversely with the degree of amnesia observed prior to reminder treatment (Cherkin, 1972; Haycock et al., 1973; Kesner \& Conner, 1974).

A second set of data said to support the generalization position comes from studies which have shown that reminder increases retention both in animals given strong training and ECS and in animals given weak training only (Gold et al. 1973; Haycock et al., 1973). Thus, in these latter studies, reminder increased retention in animals evidencing reduced retention prior to reminder regardless of how the reduced retention was affected.

Research from our laboratory (DeVietti \& Bucy, 1975; DeVietti \& Haynes, 1975) has provided results which are contrary to predictions of the generalization hypothesis. DeVietti and Bucy (1975) obtained a reminder effect in animals demonstrating a very strong initial amnesia and failed to obtain a reminder effect in animals showing an initial partial amnesia. DeVietti and Haynes (1975) found parallel increased retention in ECS animals and animals given weak training under some reminder conditions, but under a different set of reminder conditions, found 
increased retention in ECS animals but not in animals given weak training. This latter result suggests that reminder treatments produce increased retention by different mechanisms in ECS and weakly trained animals. DeVietti and Haynes suggested that reminder treatment increases retention in weakly trained animals by a mechanism similar to that detailed in the generalization hypothesis, whereas in ECS animals, reminder acts to release for behavioral expression a formerly strong, yet retrievable, memory. The studies from our laboratory used training cues and the unconditioned stressor of the original training as reminder treatment, and even though control animals showed no change in retention following reminder, the possibility that some learning was affected by the pairing of training cues with the unconditioned stressor remains. If reminder acts solely to stimulate the recall of a formerly unretrievable memory in ECS animals, the reminder treatment need not affect new learning.

Recently, we reported that animals implanted unilaterally in either the amygdaloid complex or the mesencephalic reticular formation (MRF) showed reduced retention following training relative to unimplanted controls (DeVietti \& Kirkpatrick, 1977). This, in the one-trial fear conditioning paradigm we employ in much of our research, we have defined three procedures which yield reduced levels of retention relative to standardly trained animals, namely, ECS administered after standard training (DeVietti \& Hopfer, 1974), weak training in which the trainingtrial footshock intensity and duration are reduced (DeVietti \& Haynes, 1975), and electrode implantation prior to standard training.

Previous research from our laboratory showed that, under some conditions, stimulation of the MRF increased retention in implanted animals given standard training, and additional data suggested that the stimulation of the MRF did not serve as an unconditioned aversive stimulus capable of affecting learning (DeVietti \& Kirkpatrick, 1977).

The present experiment factorially combined the presence or absence of training cues with stimulation of the MRF as reminder treatment in an attempt to increase retention in implanted animals given standard training, standard training followed by ECS, or weak training. Differences in sensitivity of these groups to reminder treatment could have important implications regarding the nature of reduced retention.

\section{METHOD}

\section{Animals and Apparatus}

The animals were male Long-Evans rats from the Central Washington State College Psychology colony, aged 90-120 days at the beginning of the experiment. The basic apparatus has been described in detail elsewhere (DeVietti \& Larson, 1971).
Two identical chambers were used for fear conditioning and testing. They measured $20 \times 30 \mathrm{~cm}$ and were $30 \mathrm{~cm}$ high. The sides and top were Plexiglas, while the back and front were aluminum painted flat gray. The grid floor was $.64-\mathrm{cm}$-diam stainless steel rods spaced $1.9 \mathrm{~cm}$ apart. A small hole just off center in the front wall allowed the insertion of a drinking tube with the orifice located approximately $5 \mathrm{~cm}$ into the chamber and $5 \mathrm{~cm}$ above the grid floor. A drinkometer circuit was formed between the water in the drinking tube and the grid floor. A $10-\mathrm{cm}$ loudspeaker for delivery of the conditioned stimulus (a 15-sec, 1,200-Hz, 90-dB tone from a Heathkit tone generator) was positioned at floor level behind a rear wall of each chamber. Both chambers were individually enclosed in lighted fan-ventilated sound-attenuation boxes. A chamber used to administer noncontingent treatments had walls constructed entirely of Plexiglas $(21 \times 56 \times 21 \mathrm{~cm}$ high $)$ with a grid floor the same size and spacing as in the training-testing chambers. This apparatus was housed in a different room from the trainingtesting chambers. Scrambled footshock, delivered through the grid floor of the conditioning chamber was either "strong" (1.6 mA, $3 \mathrm{sec}, 60 \mathrm{~Hz}, 330 \mathrm{~V} \mathrm{rms})$ or "weak" (1.0 mA, $1 \mathrm{sec}$, $60 \mathrm{~Hz}, 206 \mathrm{~V} \mathrm{rms})$. Strong footshock was also administered in the noncontingent treatment chamber. An ECS apparatus (Hayes, 1948) was set to deliver a $92-\mathrm{mA}$ shock $(200 \mathrm{msec}, 60 \mathrm{~Hz}$, $1,840 \mathrm{~V} \mathrm{rms}$ ) to the ears of the rat through wire clips fashioned to interlock with baby clothes snaps (Prisms No. 0) previously fitted to each ear. A BERL constant-current stimulator in series with a micro current amplifier was set to deliver a 60 -sec train, $6 \mathrm{sec}$ on $/ 3 \mathrm{sec}$ off, of $35-\mu \mathrm{A}, 300-\mathrm{Hz}, 1-\mathrm{msec}$ biphasic rectangular pulses with a 1-msec interpulse interval.

\section{Surgery and Histology}

The animals were anesthesized with pentobarbitol and implanted, unilaterally, with electrodes aimed at the MRF. Following system " $B$ " of Pellegrino and Cushman (1967), the implantation coordinates were $4.0 \mathrm{~mm}$ posterior to bregma, $2.00 \mathrm{~mm}$ lateral to midline, and $7.25 \mathrm{~mm}$ below the surface of the cortex. Bipolar electrodes were obtained from Plastic Products and were constructed of $0.25-\mathrm{mm}$ stainless steel wire. Upon completion of the behavioral portion of the experiment, the animals were killed, perfused with saline and $11 \%$ Formalin solution, and the electrode placements confirmed with the method of Thomson, Beeman, Conger, Reeder, Steinhilb, Wittman, and DeVietti (1978).

\section{Procedure}

After surgery, the animals were individually housed and maintained on ad-lib food and water. Following a 5-7-day recovery period, an ear snap was fitted to each ear of the animals, and the animals were handled for 5 min. During the next 4 days, the animals were given experience with the various aspects of the experimental situation according to the following schedule. On the 1st day, each rat was placed into one of the two trainingtesting chambers and left there for $10 \mathrm{~min}$. During this interval, water was removed from the home cage. The following day, each rat was taken to the chamber, its nose was gently touched to the drinking tube now present, and then released near the rear of the chamber. After the animal had completed a total of $55 \mathrm{sec}$ of contact with the drinking tube, it was returned to its home cage, where water was again available. On the 3rd day, the animals were fitted with the ECS leads and placed in the chambers for $1 \mathrm{~min}$; the home cage water was removed. The next day, the animals were again allowed to complete $55 \mathrm{sec}$ of contact with the drinking tube. The drinking tube was present in the chambers only during the two drink training days described above and on the test day described below.

On Day 5, the animals were randomly assigned to one of four treatment conditions. Animals in one group (TSFS/ECS) had the ECS leads attached and were individually placed into one of the two training-testing chambers. One minute later, the 15 -sec tone 
was presented with strong footshock, delivered through the grid floor, administered during the last $3 \mathrm{sec}$ of the tone. ECS followed $.5 \mathrm{sec}$ after offset of the tone and footshock. Animals in two other groups were treated identically except that no ECS was delivered. One group (TSFS) received strong footshock paired with the tone, and the other group (TWFS) was given weak footshock paired with the tone. The weak footshock parameters had been shown previously to yield test latencies similar to TSFS/ECS subjects (DeVietti \& Haynes, 1975). Animals in the fourth group (NCSFS/ECS) were placed in the noncontingent treatment chamber and received strong footshock and ECS. This group served as a control for any "systemic" effects of footshock and ECS.

Four days following training or noncontingent footshock, animals in each of the four major groups were given reminder treatment. Reminder consisted of one of the four combinations of training cues (present or absent) and stimulation of the MRF (present or absent). Animals given both training cues and MRF stimulation were placed in the drinking chamber with the electrode stimulating cable attached; they were presented with the 15 -sec tone $1 \mathrm{~min}$ later. Immediately following the cessation of the tone, stimulation of the MRF commenced. Animals given just training cues were treated identically except that no MRF current was passed through the electrode. Animals given just MRF stimulation were placed in a cardboard box in a different room where they received stimulation of the MRF. Finally, animals given neither training cues nor MRF stimulation simply remained in the home cage.

Additional implanted animals were treated to determine if MRF stimulation served as an unconditioned aversive stimulus capable of affecting fear conditioning. One group was given a tone-MRF stimulation pairing instead of the tone-footshock pairing on the training day and were given a second pairing 4 days later. A second group received a tone-MRF stimulation pairing, one per day, for 5 consecutive days.

All animals were tested, $24 \mathrm{~h}$ thirsty, the day following reminder treatment. The testing procedure was started by gently touching the animal's nose to the drinking tube in the chamber and releasing the rat near the rear of the chamber. After the animal had completed $50 \mathrm{sec}$ of tube contact to insure that all the animals were at a comparable baseline, the tone was automatically presented and remained on until the animal had completed an additional $5 \mathrm{sec}$ of tube contact. The time (in seconds) for the animal to complete $5 \mathrm{sec}$ of tube contact in the presence of the tone was automatically recorded and served as data for analysis. Animals not drinking within $600 \mathrm{sec}$ after the tone onset were removed from the apparatus and assigned a score of 600 .

The major design may be conceptualized as a 2 by 2 by 4 factorial, with training cues (present or absent during reminder), MRF stimulation (present or absent during reminder), and groups (TSFS, TWFS, TSFS/ECS, and NCSFS/ECS) as main effects.

\section{RESULTS}

The histology revealed that the electrode tips found to be located in the MRF clustered in an area bounded dorsally by the superior colliculus, laterally by the medial geniculate, ventrally by the medial lemniscus, and medially by the central gray. No relationship between electrode placement within the MRF and test performance was detected.

The drink latencies obtained in the presence of the specific conditioning cue, the tone, of animals with verified electrode placement in the MRF are shown in Table 1 . A 2 by 2 by 4 analysis of variance was performed on the drink latencies of animals trained or given noncontingent footshock. The analysis re-
Table 1

Test Performance in the Presence of the Tone

\begin{tabular}{|c|c|c|c|c|c|c|}
\hline \multirow[b]{2}{*}{ Group } & \multicolumn{3}{|c|}{ No Cues } & \multicolumn{3}{|c|}{ Cues } \\
\hline & $\mathrm{N}$ & $\overline{\mathbf{X}}$ & $S \bar{x}$ & $\mathrm{~N}$ & $\overline{\mathbf{x}}$ & $\mathbf{S} \overline{\mathbf{x}}$ \\
\hline & \multicolumn{6}{|c|}{ Implanted Animals-No Stimulation } \\
\hline $\begin{array}{l}\text { TSFS } \\
\text { TWFS } \\
\text { TSFS/ECS } \\
\text { NCSFS/ECS }\end{array}$ & $\begin{array}{l}8 \\
8 \\
9 \\
8\end{array}$ & $\begin{array}{r}134.50 \\
75.00 \\
109.11 \\
13.75\end{array}$ & $\begin{array}{r}20.17 \\
13.96 \\
16.44 \\
2.83\end{array}$ & $\begin{array}{l}7 \\
7 \\
8 \\
7\end{array}$ & $\begin{array}{r}213.00 \\
99.86 \\
133.63 \\
16.57\end{array}$ & $\begin{array}{r}19.93 \\
10.53 \\
17.19 \\
5.82\end{array}$ \\
\hline & \multicolumn{6}{|c|}{ Implanted Animals-Stimulation } \\
\hline $\begin{array}{l}\text { TSFS } \\
\text { TWFS } \\
\text { TSFS/ECS } \\
\text { NCSFS/ECS } \\
\text { T-MRF* } \\
\text { T-MRF** }\end{array}$ & $\begin{array}{l}8 \\
7 \\
7 \\
7\end{array}$ & $\begin{array}{r}177.75 \\
93.00 \\
103.00 \\
13.00\end{array}$ & $\begin{array}{r}30.78 \\
20.36 \\
11.09 \\
2.70\end{array}$ & $\begin{array}{l}8 \\
9 \\
8 \\
8 \\
8 \\
9\end{array}$ & $\begin{array}{r}487.75 \\
125.78 \\
261.37 \\
18.37 \\
13.87 \\
9.67\end{array}$ & $\begin{array}{r}36.27 \\
18.93 \\
35.99 \\
4.68 \\
4.32 \\
2.47\end{array}$ \\
\hline
\end{tabular}

Note-Explanation of group designations may be found in the text.

*Two pairings of the tone and MRF stimulation.

**Five pairings of the tone and MRF stimulation.

vealed that the effects obtained were complex, as the three main variables and all their interactions proved to be reliable sources of variance (all ps $<.001)$. Subsequent tests were made with the Newman-Keuls statistic with alpha set at .05.

Overall, the presentation of training cues was an effective reminder treatment as animals exposed to training cues prior to the retention test had longer drink latencies than animals not exposed to training cues. However, the analysis of the simple main effects of the Training Cues by Groups interaction, with retention performance pooled across the MRF stimulation variable, indicated that the presentation of training cues was an effective reminder treatment in the TSFS and TSFS/ECS groups but not in the TWFS and NCSFS/ECS groups, as shown in Figure 1. Additionally, as part of the breakdown of this interaction, test latencies of the TSFS/ECS and TWFS groups were found to be intermediate between the TSFS and NCSFS/ECS groups and did not differ

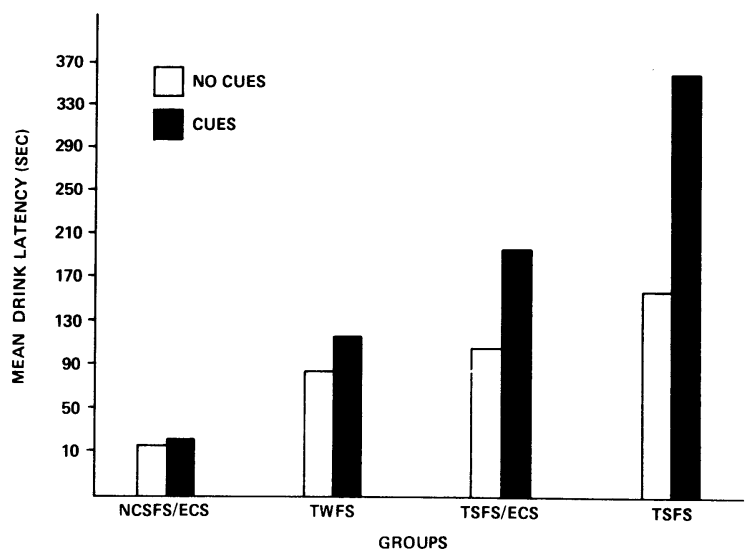

Figure 1. Retention performance of groups given exposure or no exposure to training cues as reminder treatment. 
from one another when training cues were not presented as reminder. In contrast, test latencies from all four groups differed following the presentation of training cues.

The identical pattern of results was obtained in determining the influence of stimulation of the MRF as reminder treatment. Overall, MRF-stimulated animals had longer drink latencies than animals not given MRF stimulation. However, the analysis of the interaction between MRF stimulation and groups, with retention performance pooled across the exposure to training cues conditions, indicated that the drink latencies of the TSFS and TSFS/ECS groups, but not those of the TWFS or the NCSFS/ECS groups, were increased by MRF stimulation, as shown in Figure 2. With no MRF stimulation administered, TSFS/ECS and TWFS animals showed test latencies intermediate between the TSFS and NCSFS/ECS groups and did not differ from one another. However, the test latencies of all four groups were different following MRF stimulation.

Analysis of the simple main effects of the training cues by MRF stimulation interaction, with test performance pooled across groups, indicated that the presentation of training cues increased test latencies regardless of whether MRF stimulation followed, but that MRF stimulation increased test latencies only when preceded by training cues.

The analysis of the triple interaction between training cues, MRF stimulation, and groups provided for a finer resolution of the reminder effects in the various groups. Although trends are obvious in Table 1, the trained groups given neither training cues nor MRF stimulation as reminder did not differ statistically from one another, although all three of these groups had longer drink latencies than the NCSFS/ECS group. No combination of reminder treatment influenced test latencies in the NCSFS/ECS group and, without preceding exposure to training cues, stimulation of the MRF did not influence

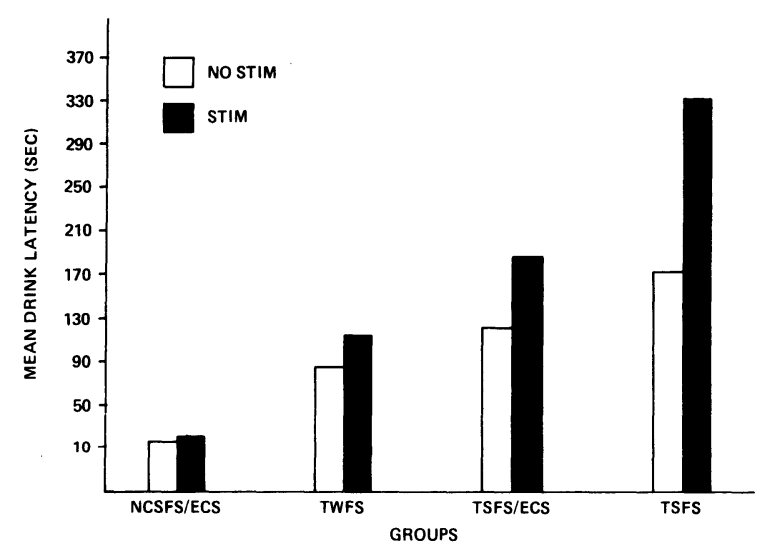

Figure 2. Retention performance of groups given stimulation or no stimulation of the mesencephalic reticular formation as reminder treatment. drink latencies in the three trained groups. Exposure to training cues without following MRF stimulation increased drink latencies in the TSFS group but not in the TSFS/ECS or TWFS groups. The combination of training cues and stimulation of the MRF increased drink latencies in both the TSFS and TSFS/ ECS groups but to a greater extent in the TSFS group. The combination of training cues and stimulation of the MRF was without effect in the TWFS group.

Additional analyses with $t$ tests, using the error term from the main analysis in the estimate of the standard error, evaluated the specific influence of the reminder manipulations. In each group, comparisons were determined between animals given neither training cues nor MRF stimulation and animals given training cues alone, MRF stimulation alone, or both training cues and MRF stimulation. These comparisons revealed that none of the reminder combinations modified test performance in the NCSFS/ ECS or TWFS groups, although there was a strong trend toward increased test latencies in the TWFS group given both cues and MRF stimulation $(p=.07)$. The presentation of training cues alone and in combination with MRF stimulation, but not MRF stimulation alone, increased drink latencies in the TSFS group. In contrast, the combination of training cues and MRF stimulation, but not training cues or MRF stimulation alone, increased retention performance in the TSFS/ECS group.

Comparison between the two groups given either two or five tone-MRF stimulation pairings failed to show that they differed in their test performance. Further, the pairing of the tone with MRF stimulation did not appear to result in measurable fear conditioning, as neither group differed from any of the NCSFS/ECS groups and significant differences were obtained between the two tone-MRF stimulation groups and the groups trained by pairing the tone with footshock.

\section{DISCUSSION}

The analysis of the test latencies indicated that the four basic groups were differentially sensitive to the reminder treatments. Overall, reminder was most effective in the TSFS group, less effective in the TSFS/ ECS group, marginally effective in the TWFS group, and ineffective in the NCSFS/ECS group.

The two current explanations of the reminder effect vary considerably. To reinterate, those who hold to the notion that amnesic treatments disrupt memory storage believe that reminder produces new learning which generalizes to and summates with a memory remnant which survived the amnesic treatment. Those believing that amnesic treatment disrupts memory retrieval view reminder as releasing memory formerly suppressed by the amnesic treatment. 
Neither of these two explanations appears completely supported by the present data.

New learning as a consequence of reexposure to training cues alone or training cues followed by stimulation of the MRF as reminder treatment seems unlikely. Presentation of training cues in the absence of reinforcement, footshock, operationally defines an extinction trial-a procedure which decreases, not increases, a response tendency. However, the pairing of training cues with stimulation of the MRF might produce new learning if MRF stimulation were aversive. Evidence against the notion the MRF stimulation was an aversive event was found in a previous study (DeVietti \& Kirkpatrick, 1977) where rats failed to modulate stimulation of the MRF in a tilt-box task with stimulation parameters similar to those used in the present study. Additional data (unpublished) with the identical MRF stimulation parameters used in the present study showed that only 2 of 34 rats modulated the stimulation in the tilt box in a manner suggesting that the stimulation was aversive. In short, under these conditions, stimulation of the MRF does not appear to be aversive and thus would seem incapable of serving as an unconditioned stimulus for learning. Further support for this notion comes from the performance of groups included in the present study. Without preceding training cues, stimulation of the MRF did not increase retention performance in any group, and, more to the point, animals given two or five pairings of training cues and MRF stimulation failed to demonstrate any measurable fear conditioning. Also, NCSFS/ECS animals given training cues and stimulation of the MRF as reminder treatment failed to change their retention performance.

However, the notion that the pairing of training cues and stimulation of the MRF did not produce new learning in animals previously fear conditioned is not so easily dismissed. TWFS animals did show a small, and technically insignificant, increase in retention performance following this reminder treatment. It may be that this slight increase in retention performance reflects new learning which may be observed only in animals which have experienced previous training. This possibility is entertained further by Gold et al. (1973).

The notion that reminder treatment produced new learning in trained animals in inadequate to totally explain the increase in retention performance demonstrated in the TSFS and TSFS/ECS groups. This is so because the increase in performance in these groups was differentially greater than that observed in the TWFS group. If reminder served as a learning trial and this was the sole effect of the treatment, learning from this "trial" would be expected to produce parallel, not differential, increases in retention in all trained groups. Parallel increases in retention performance did not occur. We view this result as consistent with the notion posited earlier (DeVietti \& Haynes, 1975) that reminder may increase retention in weak trained animals by producing new learning which summates with previous training. However, in animals demonstrating reduced retention of strong training because of experimental treatments, reminder increases retention by releasing for behavioral expression a strong memory formerly suppressed by these treatments.

If ECS acted solely by disrupting memory retrieval mechanisms, one might expect equal effects of reminder treatments in the TSFS/ECS and TSFS groups. Several aspects of the present data suggested that the TSFS group was more sensitive to reminder than the TSFS/ECS group. It may be that this pattern of results is best explained by assuming that ECS affects memory storage and memory retrieval, whereas the implantation procedure affects only memory retrieval. An alternative explanation of the difference in performance following reminder in these two groups may be that the reminder treatment was not maximized in ECS animals. Some support for this view may be found in the fact that presentation of training cues alone produced a significant increase in retention performance in TSFS animals but not in TSFS/ECS animals.

Whatever the memory process or processes modified by implantation and ECS and implantation alone, much work remains to be done in identifying the neurophysiological mechanisms involved. Perhaps we must wait until these mechanisms are identified before we will be able to determine whether experimental treatments which reduce retention modify memory storage, memory retrieval, or both processes.

\section{REFERENCES}

Cherkin, A. Retrograde amnesia in the chick: Resistance to the reminder effect. Physiology \& Behavior, 1972, 8, 949-955.

Coons, E. E., \& Miller, N. E. Conflict versus consolidation of memory traces to explain "retrograde amnesia" produced by ECS. Journal of Comparative and Physiological Psychology, $1960,53,524-531$.

DeVietri, T. L., \& BucY, C. E. Recovery of memory after reminder: Evidence for two forms of retrieval deficit induced by ECS. Physiological Psychology, 1975, 3, 19-25.

DeVietti, T. L., \& Haynes, D. Reminder: Similar and differential effects in amnesic and weakly trained rats. Physiological Psychology, 1975, 3, 265-269.

DeVietTi, T. L., \& Hopfer, T. M. Complete amnesia induced by ECS and complete recovery of memory following reinstatement treatment, Physiology \& Behavior, 1974, 12, 599-603.

DEVIETTI, T. L., \& KirkPatrick, B. R. Specific stimulation of the brain in rats modifies retention for both newly acquired and old habits. Journal of Comparative and Physiological Psychology, 1977, 91, 662-673.

DEVIETTI, .T. L., \& LARSON, R. C. ECS effects: Evidence supporting state-dependent learning in rats. Journal of Comparative and Physiological Psychology, 1971, 74, 407-415. 
Glickman, S. E. Preservative neural processes and consolidation of the memory trace. Psychological Bulletin, 1961, 58, 218-233.

Gold, P. E., Haycock, J. W., Macri, J., \& McGaugh, J. L. Retrograde amnesia and the "reminder effect": An alternative interpretation. Science, 1973, 180, 1199-1201.

Haycock, J. W., Gold, P. E., Macri, J., \& McGaugh, J. L. Noncontingent footshock attenuation of retrograde amnesia: A generalization effect. Physiology \& Behavior, 1973, 11, 99-101.

HAYES, K. J. Cognitive and emotional effects of electroconvulsive shock in rats. Journal of Comparative and Physiological Psychology, 1948, 41, 40-61.

Kesner, R. P., \& Conner, H. S. Cue-dependent recovery from ECS-induced amnesia: Evidence for time dependence. Physiological Psychology, 1974, 2, 123-125.

LEWIS, D. J. Sources of experimental amnesia. Psychological Review, 1969, 76, 461-472.

LEWIS, D. J. A cognitive approach to experimental amnesia. American Journal of Psychology, 1976, 89, 51-80.

LEwIS, D. J., \& MAHER, B. A. Neural consolidation and electroconvulsive shock. Psychological Review, 1965, 72, 225-239.

Lewis, D. J., Misanin, J. R., \& MilleR, R. R. Recovery of memory following amnesia. Nature, 1968, 220, 704-705.
McGAUGH, J. L. Time-dependent processes in memory storage. Science, 1966, 153, 1331-1358.

Miller, R. R., \& SPRINGER, A. D. Induced recovery of memory in rats following electroconvulsive shock. Physiology \& Behavior, 1972, 8, 645-651.

Miller, R. R., \& Springer, A. D. Amnesia, consolidation, and retrieval. Psychological Review, 1973, 80, 69-79.

Pellegrino, L. J., \& Cushman, A. J. A stereotaxic atlas of the rat brain. New York: Appleton-Century-Crofts, 1967.

Quartermain, D., McEwen, B. S., \& Azmitia, E. C., JR. Amnesia produced by electroconvulsive shock or cycloheximide: Conditions for recovery. Science, 1970, 169, 683-686.

Spevack, A. A., \& Suboski, M. D. Retrograde effects of electroconvulsive shock on learned responses. Psychological Bulletin, 1969, 72, 66-76.

Thomson, J. H., Beeman, F. J., Conger, G. L., Reeder, W. T., Steinhilb, K. R., Wittman, T. K., \& DeVietti, T. L. Videotape technology in the identification and storage of intracerebral electrode locations. Physiology \& Behavior, 1978, 20, 487-489.

(Received for publication November 8, 1976; revision accepted April 3, 1978.) 